\title{
Towards near zero energy dwellings by heat pump implementation in HVAC plants
}

\author{
L. Schibuola, S. Martini, M. Scarpa \& C. Tambani \\ Department of Design and Planning in Complex Environments, \\ University Iuav of Venice, Italy
}

\begin{abstract}
The EPBD (Energy Performances of Buildings Directive) updated on 9 July 2010 imposes new rules for energy savings in buildings. By 31 December 2020 all new buildings must be nearly Zero Energy Buildings (nZEB) with reference to the consumption of fossil fuels. The roadmap that each nation is adopting for this purpose imposes a further significant increase in the share of the building energy requirement covered by renewable energy. Achieving this goal at acceptable costs for the communities represents a real challenge considering the current state of the art. The role of Eco-Architecture will be fundamental in this phase of introduction and spread of innovative techniques in the design of building-plant system. For this aim, the installation of heat pumps for building heating is able to contribute significantly in terms of better energy performance and exploitation of renewable energy. In fact, in the EPBD the energy from heat sources of heat pumps (air, ground, water) is considered renewable energy. An assessment about the possibilities and limits of the electric heat pump installation in dwellings is here reported for different case studies and climates in Europe. Keywords: EPBD, nZEB, heat pump, dwelling, HVAC plants, renewable energy sources, $\mathrm{CO}_{2}$ reduction, SEER, energy efficiency, solar plants.
\end{abstract}

\section{Introduction}

The newly recast directive on the energy performance of buildings EPBD [1] demands nearly Zero Energy Buildings (nZEB) for all new buildings. The elaboration of specific rules to obtain this result is entrusted to member states but the general promoting of the use of renewable energy sources (RES) will anyway lead to the requirement of a strong increment of the RES share referring to the 
total energy delivered to buildings. For example in the Italian legislation [2] this share will have to grow up to $35 \%$ by 2016 and $50 \%$ by 2017 . For this aim the EU directive recognizes heat pump as a key enabling technology using RES from air, water and ground. The amount of annual renewable energy $E_{R E S}$ from an electric heat pump will be calculated as described in the annex VII of the EPBD directive:

$$
E_{R E S}=Q_{u s a b l e} *(1-1 / S P F)
$$

$Q_{\text {usable }}$ is the total usable heat delivered by the heat pump for space heating and domestic hot water (DHW) production. $S P F$ is the seasonal performance factor i.e. the average heat pump efficiency referred to the whole working period. But only heat pumps which achieve $115 \%$ efficiency based on primary energy use should be taken into account. It means that $S P F$ must be:

$$
S P F>1.15 * 1 / \eta
$$

where $\eta$ is the ratio between the total gross production of electricity and the primary energy consumption for electricity production and it is calculated as an EU average by EUROSTAT. Actually its official value is 0.4 and consequently the SPF lower limit is 2.875 . By dynamic simulation of building-plant system the heat pump contribution to increase the total RES quota in dwellings is investigated here.

\section{Heat pump modelling}

In the most famous and diffuse computer programs for the dynamic simulation, we normally find a method to evaluate the average performance of the plant in steady state conditions in each time step of the simulation. As regards the reversible heat pump, the procedure is based on the use of working curves from the manufacturer and it consists of two phases. First the calculation of the capacity and of the coefficient of performance $C O P$ in heating mode (or energy efficiency ratio EER in cooling mode) at full load operating conditions normally as a functions of the thermal levels of the external fluids exchanging heat fluxes with the machine at the condenser and evaporator. Then a capacity ratio $(C R)$ is calculated as the ratio of the building demand really supplied by the machine in the time step to the maximum energy which could be supplied in the same interval in the case of continuous working at full capacity. The part load influence is taken into account by multiplying the full load $C O P$ for a part load factor $(P L F)$.

In figure 1 the trend of the $P L F$ as a function of $C R$ is reported in the cases of on off or modulating control of the capacity for a single compressor machine. The modulation is obtained by an inverter, an electronic device able to vary the speed of the electric motor of the compressor. Simplified models of PLF can be obtained from some experimental tests (Bettanini et al. [3]). 

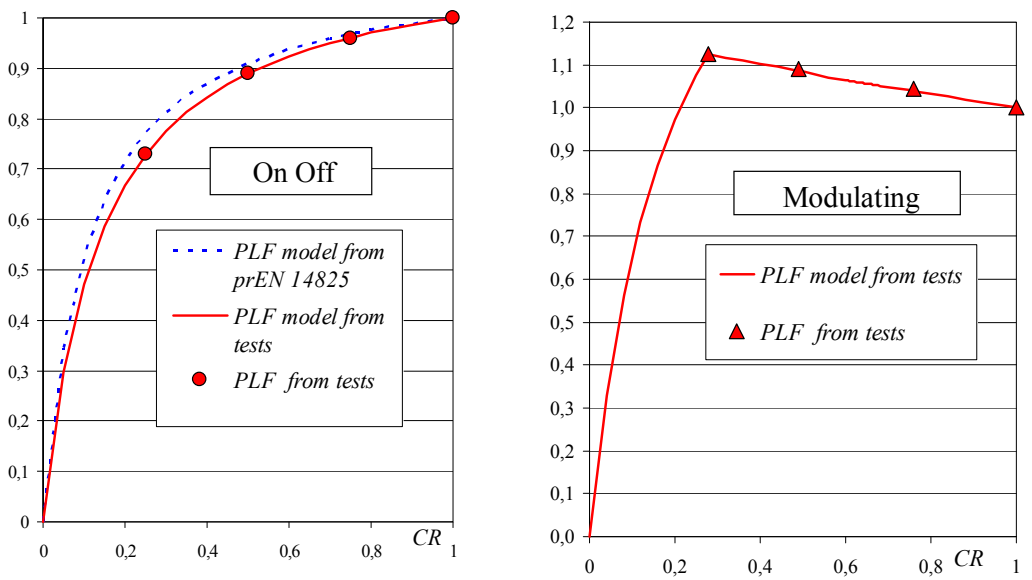

Figure 1: $\quad$ Part load factor $P L F$ as a function of the capacity ratio $C R$ for on off or modulating control of capacity.

For on off control, the prEN 14825 CEN [4] suggests the use of the following model in absence of test data:

$$
P L F=\frac{C R}{0.9 \cdot C R+0.1}
$$

In the field of the modulation of capacity PLF can be obtained by linear interpolation between test values, below the limit of possible modulation we have again an on off behavior.

\section{Case studies}

Three typical buildings representative of well diffuse dwelling typologies in Europe have been considered: a single house, a terraced house and a block of four flats. Three climatic conditions: London, Milan and Rome. In figures 2, 3 and 4, a view and an exploded view of the three buildings are reported. Standard materials for the envelopes are presented with a thermal transmittance in accordance with local regulations. A constant natural ventilation equal to 0.3 air change for hour. The maximum occupancy level is 4 persons for each residential unit and an internal load of $8 \mathrm{~W} / \mathrm{m}^{2}$, both variable during the day with a typical scheduling. Fan coils or radiant panels are the two plant alternatives with intermittent working from 7 a.m. to 9 p.m. every day.

The heating period is fixed by local regulations and the air conditioning is from June to September. Air to water reversible heat pumps have been considered. In fact, air source heat pumps are certainly the most diffuse in Europe and normally used also for the air conditioning period. Small commercial machines, with nominal capacity between 6 to $17 \mathrm{~kW}$ depending on the cases, 

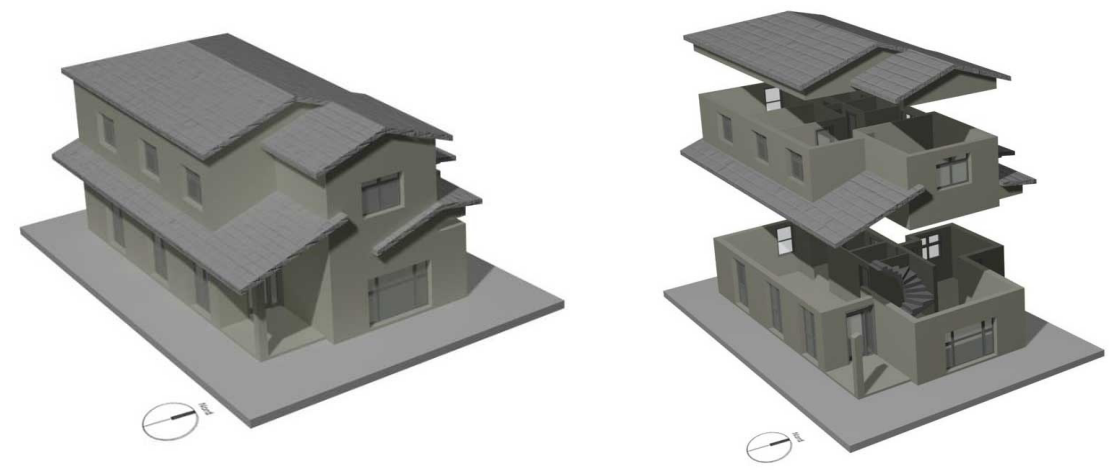

Figure 2: View and exploded view of the single house, net floor area $200 \mathrm{~m}^{2}$, heated volume $540 \mathrm{~m}^{3}$.
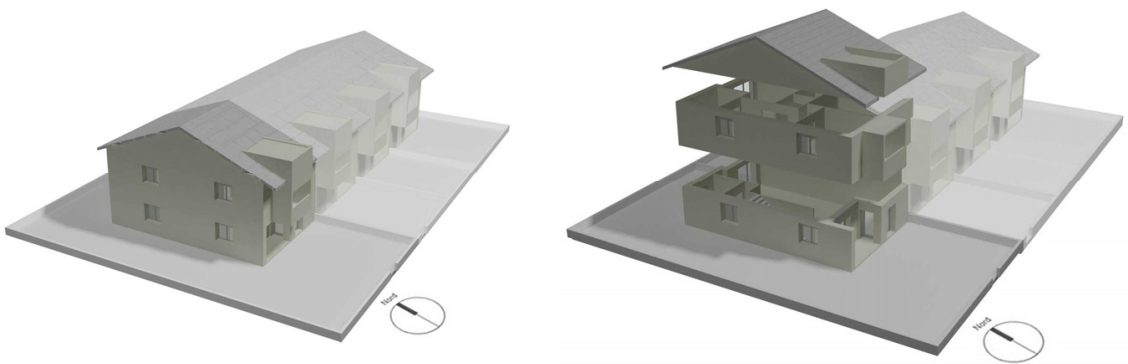

Figure 3: View and exploded view of the terraced house, net floor area $158 \mathrm{~m}^{2}$, heated volume $427 \mathrm{~m}^{3}$.

with only one scroll compressor and R410 refrigerant have been investigated. The control of capacity can be on off or modulating by inverter.

The DHW demand is estimated in 751 /day per person at $40^{\circ} \mathrm{C}$. As mandatory in many EU member states, a solar plant for the DHW production is always foreseen in these cases. The energy performances of these flat plate collector solar plants have been simulated on hourly basis by using TRNSYS code (Klein et al. [5]). The collector area is always sized to provide a solar fraction next to $65 \%$ of the annual energy required for DHW production. This is a typical value for a cost effective thermal solar plant. The heat pump provides the auxiliary energy for DHW during the whole year.

The dynamic simulation of building-plant system is based on the use of the DesignBuilder software, DesignBuilder Software Ltd [6], user interface of the well-known calculation algorithm implemented in the EnergyPlus program (Crawley et al. [7]), today internationally considered the most reliable code for building load calculation. 

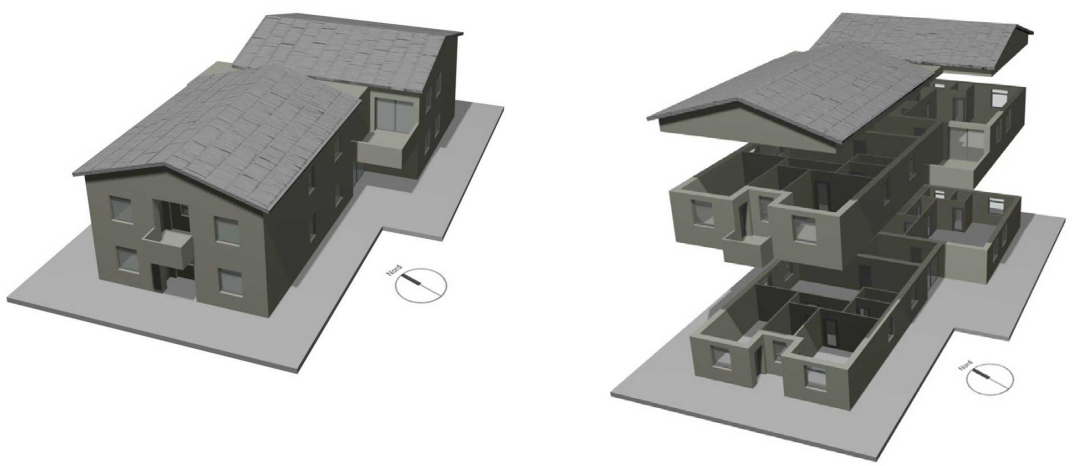

Figure 4: $\quad$ View and exploded view of the block of four flats, net floor area $384 \mathrm{~m}^{2}$, heated volume $1037 \mathrm{~m}^{3}$.

\section{Results}

For the various application cases, fig. 5 provides the $S P F$ of the heat pump for the space heating in winter and the annual DHW production. In fig. 6, the seasonal mean EER (SEER) is reported for the cooling mode of the machine in summer. As you can see in these figures, these efficiencies are strongly increased in the radiant panel cases owing to the most favorable temperatures of the cold or hot water produced: $18^{\circ} \mathrm{C}$ and $35^{\circ} \mathrm{C}$ respectively. Instead for fan coil supply these water temperatures are $7^{\circ} \mathrm{C}$ and $45^{\circ} \mathrm{C}$ respectively. In addition, the seasonal

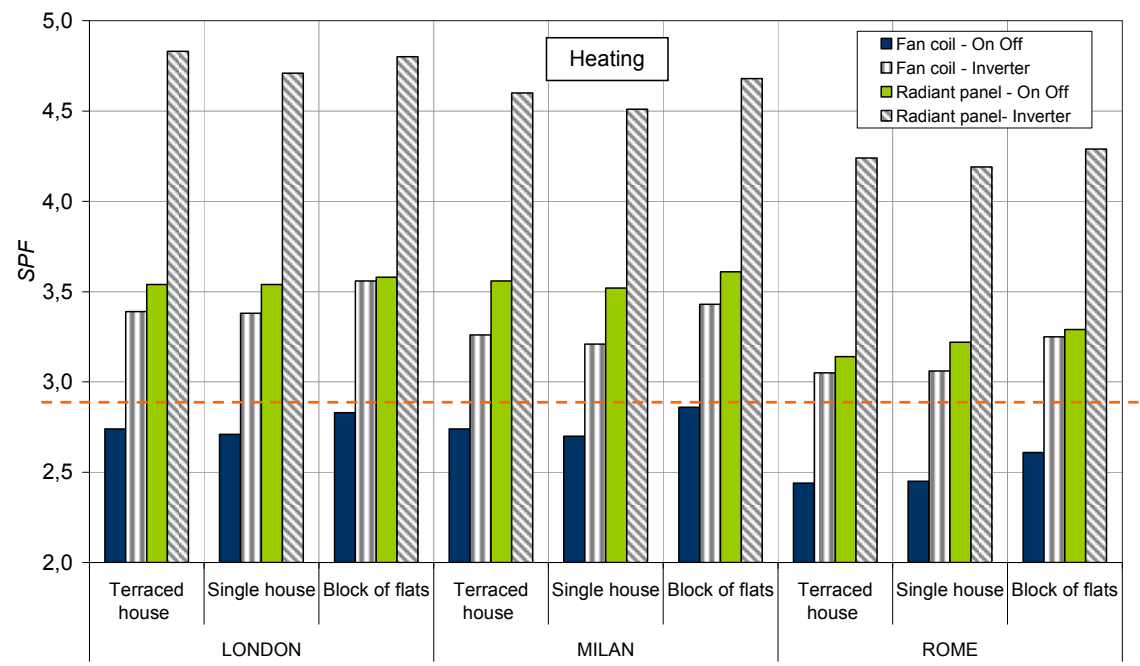

Figure 5: $\quad$ Seasonal performance factor $(S P F)$ of the heat pump in the various investigated cases. The dotted line is the $S P F$ limit. 


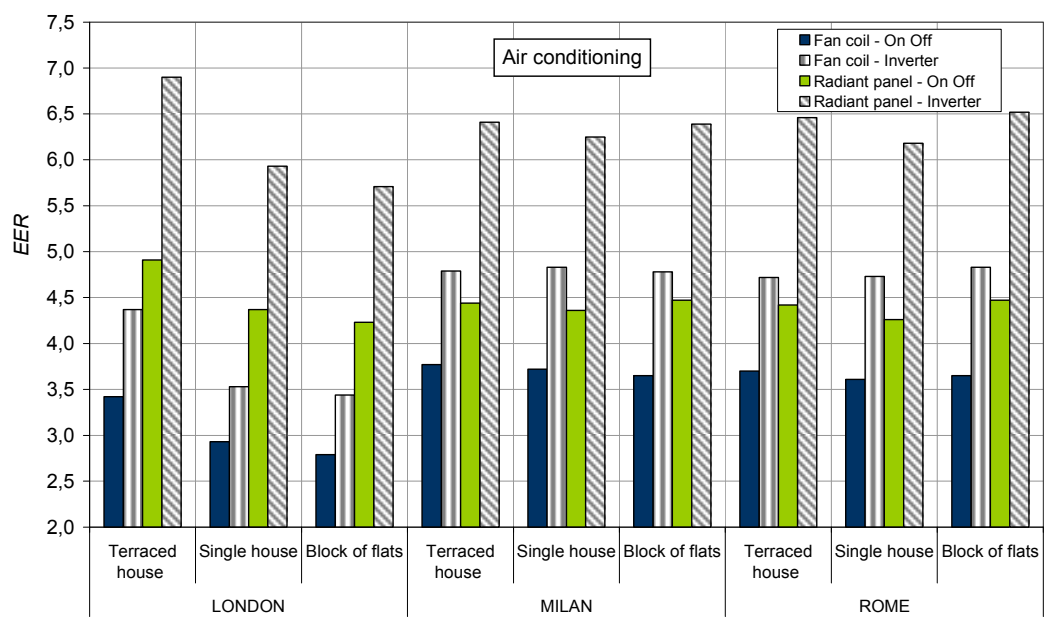

Figure 6: Seasonal energy efficiency ratio (SEER) in the various investigated cases.

efficiencies are deeply influenced by the behavior of the machines in part load working conditions. The presence of the inverter permits an efficiency increment between $20 \%$ and $30 \%$ with respect to on off control.

But in the case of high part load and therefore of working in the on off field also with inverter equipped machines, the part load penalization is evident in the mild climates (Rome) in winter.

The worst efficiencies are with fan coils and on off control In this occurrence the $S P F$ results always less than 2.875 limit indicated in the picture with the dotted line and therefore the EC directive establishes that the heat pump effects cannot be taken into account for the $\mathrm{E}_{\mathrm{RES}}$ balance.

In order to reduce the part load penalization a suitable model of a stratified heat storage, a water tank to be coupled to the inverse cycle machine, has been introduced.

In this way the heat pump works to reload this storage which supplies the user plant. The tank volume is sized to have a $C R$ of the machine never less than 0.5 . An investigation about the effects of the storage has been carried on in the case of on off control which is the most critical.

In fig.7 the comparison of $S P F \mathrm{~s}$ and SEERs with or without storage is presented for Milan. We can often observe a small efficiency increase with the storage. In fact the effect of a higher $P L F$ is partially reduced by a less favorable thermal level of the hot or cold water produced by the machine owing to the tank loading exigency. In fact in order to have an adequate thermal inertia in the storage, the internal water temperature set point is $50^{\circ} \mathrm{C}$ in heating and $4{ }^{\circ} \mathrm{C}$ in cooling mode in fan coil cases. In presence of radiant panel these temperatures are $40^{\circ} \mathrm{C}$ and $13^{\circ} \mathrm{C}$ respectively. But this increase is able to give $S P F$ values always greater than the limit of 2.875 and this is fundamental to introduce the heat pump contribution in the $E_{R E S}$ balance. 


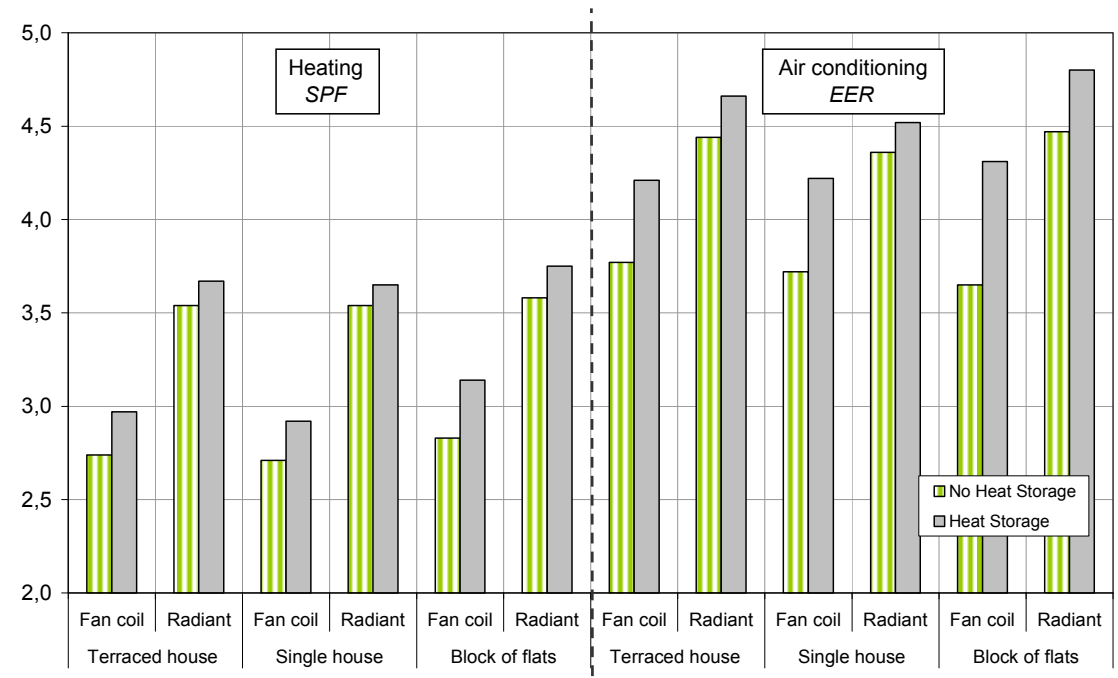

Figure 7: Comparison between seasonal efficiencies, SPFs and SEERs, with or without the heat storage in the various case studies with on off control in Milan.

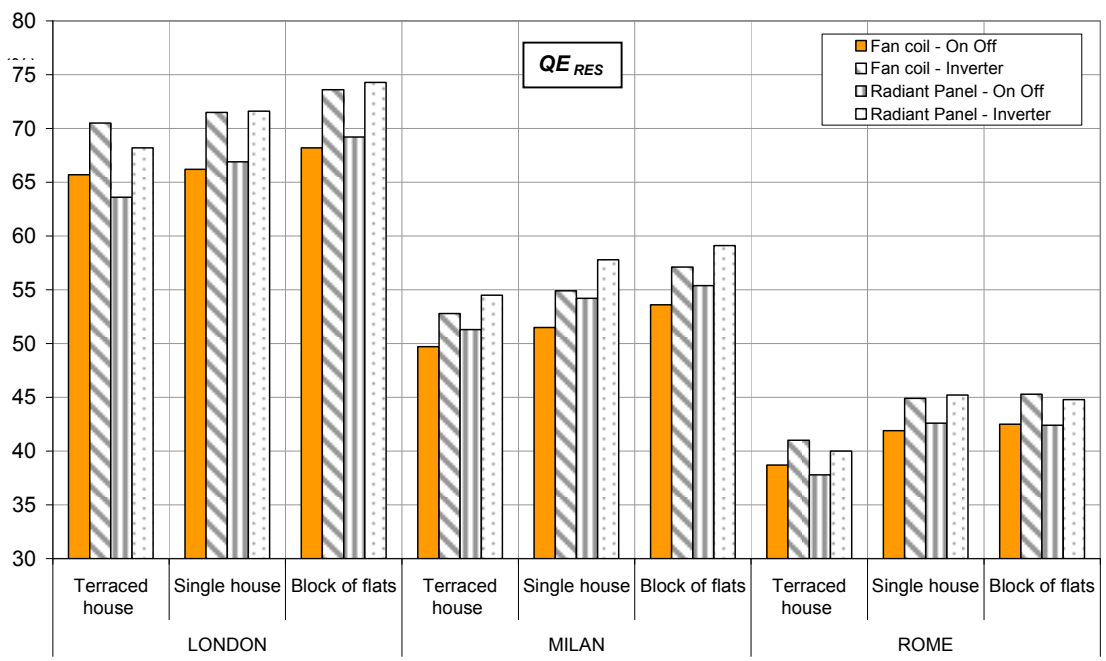

Figure 8: Renewable energy quota $Q E_{R E S}(\%)$ in the various study cases without heat storage.

For each case the global amount of $E_{R E S}$ has been assessed by considering the renewable energy from the solar plant and the aerothermal energy contribution of the heat pump calculated by equation (1) for space heating and to provide 
auxiliary heat for DHW production. Figure 8 presents the ratio $Q E_{R E S}$ between the $E_{R E S}$ and the annual delivered energy to the buildings in the various case studies. This delivered energy is calculated by considering the primary energy consumptions of the reversible heat pump for heating and cooling and the auxiliary consumptions of the HVAC and solar plants. As only the cases without heat storage are presented, it is possible to notice that even in the occurrence of $S P F$ less than the 2.875 limit, with fan coils and on off control, the $Q E_{R E S}$ can be very favorable and it often goes over $50 \%$.

This result suggests a reconsideration of the restriction about $S P F$. Instead the real problem is represented by the air conditioning consumption. In the mild climate when the air conditioning effort becomes dominant if compared with heating, the annual $Q E_{R E S}$ is significantly lower than in Northern and Central Europe. Just in Rome with the best $S P F$, the $Q E_{R E S}$ is not able to go over $46 \%$ and it is sometimes limited to $20 \%$ while in London with the inverter control it is over $65 \%$. In order to achieve a remarkable increment of $Q E_{R E S}$ also in the Southern Europe the use of active or passive solar systems for building heating is certainly useful, but not sufficient. Instead fundamental it is the introduction of technologies to exploit the renewable energies also in summer air conditioning. Natural ventilation and solar cooling can reduce the cooling demand covered by the electric machine. The heat recovery from the condenser of the inverse cycle machine can give an important contribution to DHW production. These opportunities and consequently the procedures to calculate their benefits with respect of $Q E_{R E S}$ must be take into account in the European standard following EPBD.

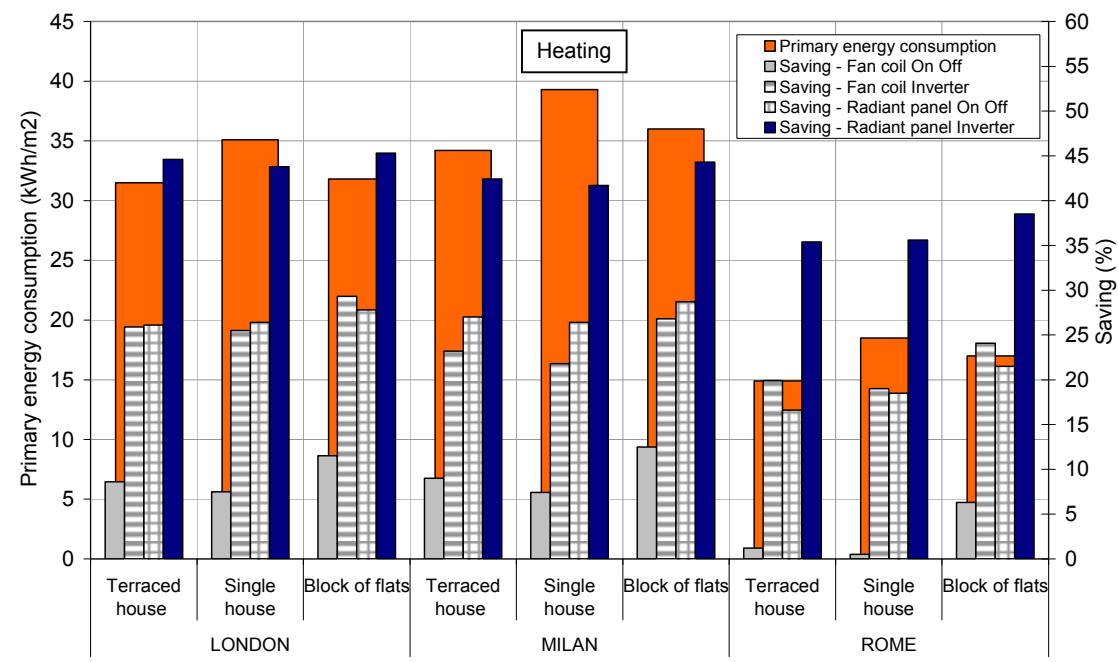

Figure 9: Percentage savings with the use of heat pumps. This saving is referred to the indicated primary energy yearly consumption $\left(\mathrm{kWh} / \mathrm{m}^{2}\right)$ in the case of a condensing boiler. 
In figure 9 the percentage energy savings obtained with the introduction of the heat pumps are presented for the various case studies. These savings are referred to the primary energy consumption about space and DHW heating requirements with the alternative of gas boilers to produce the heat necessary. High efficiency condensing boilers have been considered with a typical mean seasonal efficiency equal to 1.0 in fan coil plant and 1.02 with radiant panels.

Despite this, the energy savings can become very remarkable reaching sometimes values about $45 \%$. The advantage appears strongly affected by the introduction of technical solutions able to improve the $S P F$ like capacity control by inverter and radiant panels.

The possibility to reduce exhausted gas emissions in the urban centers is another fundamental opportunity connected with the introduction of the electric heat pump in alternative to the boiler.

In fig. 10 the annual $\mathrm{CO}_{2}$ emission amounts per net floor area unit owing to the use of gas boilers are showed for the different dwelling types and climates. The elimination of these local emissions can be a significant contribution to the environmental health not only at urban level but also in the context of the future electric energy grids characterized by highly distributed electric energy production from RES like photovoltaic systems or wind generators which will reduce the intervention of traditional power station supplied by fossil fuels.

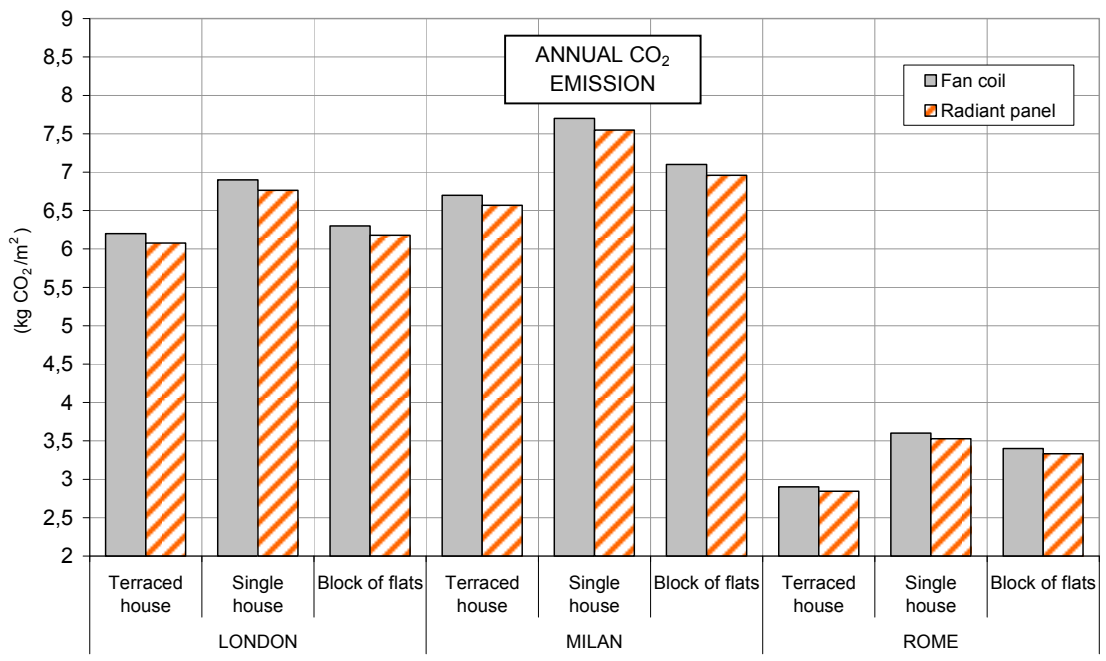

Figure 10: Annual $\mathrm{CO}_{2}$ emissions per net floor area unit by condensing boilers with fan coil or radiant panel plants in the case studies here considered.

\section{Conclusions}

The introduction of the heat pump in alternative to the boiler for space and DHW heating is able to give a fundamental contribution to achieve the goal of nZEBs 
respecting the 2020 deadline in Northern and Central Europe. Instead in the Southern Europe it is essential to flank the heat pump use during the air conditioning period with other technical solutions exploiting solar energy and the heat recovery from the machine. But to collect a full advantage, low temperature HVAC plants and heat pumps equipped with optimized capacity control must be adopted.

Another not negligible aspect is the passage to only electric demand house thanks to electric heat pumps and induction cooking.

The elimination of local exhausted gas emissions in buildings located in the urban isles is certainly a further progress towards a better environmental quality inside the cities.

\section{References}

[1] EU Community, Energy Performance Building Directive EPBD (recast), directive 2009/28/EC, April 2009.

[2] Italian Decree n. 28/11, Transposing of the directive 2009/28/CE on the promotion of the use of energy from renewable sources, March 2011.

[3] Bettanini, E., Gastaldello, A., Schibuola, L., Simplified models to simulate part load performances of air conditioning equipments. Proc. of the $8^{\text {th }}$ Int. Conf. of the International Building Performance Simulation Association (IBPSA), Eindhoven, Netherlands, pp. - 107-114, 2003.

[4] CEN, prEN 14825 Air conditioners, liquid chilling packages and heat pumps, with electrically driven compressors, for space heating and cooling Testing and rating at part load conditions and calculation of seasonal performances, final draft, October 2011.

[5] Klein et al., TRNSYS v.17 2010 - A Transient System Simulation Program, User Manual. University of Wisconsin-Madison US, http://sel.me.wisc.edu /trnsys.

[6] DesignBuilder Software Ltd, DesignBuilder program 2012 v. 3.0, Stroud Gloucestershire, UK, http://www.designbuilder.co.uk

[7] Crawley, B. D., Lawrie, K. L., Winkelmann, F. C., Pedersen C.O., EnergyPlus: new capabilities in a whole-building energy simulation program, the $7^{\text {th }}$ Int. Conf. of the International Building Performance Simulation Association (IBPSA), Rio de Janeiro, Brazil, pp. 51-58, 2001. 